\title{
Addressing medical errors: an intervention protocol for nursing professionals
}

\author{
Abordaje de los errores asistenciales: protocolo de \\ intervención para profesionales de enfermería \\ Abordagem dos erros assistenciais: protocolo de intervenção para profissionais de enfermagem
}

How to cite this article:

Díaz Pérez C, Salvadores Fuentes P, Jiménez García E. Addressing medical errors: an intervention protocol for nursing professionals. Rev Esc Enferm USP. 2019;53:e03463. DOI: http://dx.doi.org/10.1590/S1980-220X2018012703463

\section{Cristina Díaz Pérez ${ }^{1}$ \\ Paloma Salvadores Fuentes ${ }^{2}$ \\ Elena Jiménez García ${ }^{1}$}

* Extracted from the research project:

"Estratégias de integração em rede: contribuições do enfermeiro", Programa de Pós-Graduação em Enfermagem, Universidade Federal do Paraná.

1 Universidad Pontificia de Salamanca, Facultad de Ciencias de la Salud "Salus Infirmorum", Madrid, Spain.

${ }^{2}$ Universidad Rey Juan Carlos de Madrid, Madrid, Spain.

\section{Corresponding author:}

Cristina Díaz Pérez

Facultad de Ciencias de la Salud "Salus Infirmorum"

Dirección postal: Calle de Gaztambide 12

28015 - Madrid, Spain.

cdp.urg@gmail.com

\begin{abstract}
Objective: To identify the types of interventions that should be included in an organizational protocol for responding to serious adverse events involving nursing staff. Method: A descriptive exploratory study was conducted in the Autonomous Community of Madrid, Spain using a questionnaire. Results: 248 nurses have participated. The respondents prioritized the following interventions for inclusion in the protocol: legal advice ( $86.5 \%$ of participants) and counseling (82.4\% of participants). Over two-thirds of the nurses $(69.3 \%)$ showed that they would like to receive guidance on how to record adverse events on the patient's medical records, while $64.8 \%$ showed that they would like to receive advice on assurances and legal safeguards in relation to the health organization's medical error notification system and 54.5\% endorsed refresher training. Compulsory temporary or permanent transfer of nursing staff involved in adverse events was one of the least popular interventions (3.3\% of participants). Conclusion: The nurses prioritized counseling, legal advice, training in communication techniques, and refresher training to address the consequences of adverse events and discarded the possibility of compulsory temporary or permanent transfer.
\end{abstract}

\section{DESCRIPTORS}

Patient Safety; Medical Errors; Medication Errors; Nursing; Team. 


\section{INTRODUCTION}

Adverse events are traumatic and painful experiences for both patients and their families and involved healthcare professionals ${ }^{(1)}$. Although patients are considered the first victims of medical error, the professionals involved also suffer losses and may be regarded as "second victims"(2-3).

Nurse second victims may be defined as nursing professionals who suffer emotional and moral symptoms from their involvement in medical errors resulting in serious harm to the patient ${ }^{(4)}$.

When a sanitary professional is involved in a commission of a derived error from provided assistance, they experience many emotional consequences subsequent to the event that should be detected and addressed as early as possible ${ }^{(2,5)}$. These symptoms include guilt, anxiety, exhaustion, lack of concentration, and fear of legal action and of reliving the event repeatedly ${ }^{(4,6-7)}$. In addition, the affected professional may be impaired in performing usual roles for days or weeks ${ }^{(3)}$.

When a medical error resulting in serious harm to the patient is committed, such as a medication error for example, the patient is of first importance. However, it is crucial not to overlook the importance of providing psychological support to the involved professionals ${ }^{(2,5,8)}$.

In this respect, healthcare organizations should develop procedures that safeguard the right of professionals involved in preventable adverse events to receive just and compassionate treatment ${ }^{(9)}$.

Second victims are often unable to continue working after a preventable adverse event, usually requiring special leave, and can ultimately abandon the nursing profession ${ }^{(6)}$. Despite these problems, few healthcare organizations have developed procedures for assisting second victims who are unable to cope with the situation ${ }^{(10)}$.

The involved healthcare organization may be considered the third victim due to the loss of reputation suffered as a consequence of an adverse event $t^{(1,11)}$.

Health managers and organizational leaders must implement second victims help interventions, based on a nonguilty professionals culture ${ }^{(12-13)}$. An adequate institutional leadership should provide the implementation of a response protocol in face of adverse events built in a set of consensual and endorsed actions, by the professionals themselves ${ }^{(14-16)}$.

The establishment of protocols to support the professionals that are involved in an adverse event and to the sanitary organization would serve as an instrument to know how, when and who would be responsible for each function ${ }^{(6,9)}$. Procedures directed to endorse these professionals should be implanted in situ, inside the units or health center services, by nurse directors, unit managers, peers, and professional colleagues ${ }^{(4)}$.

Besides communication and apology strategies that report the errors, healthcare professionals call for safeguards against legal action, with the assurance of appropriate proceedings for all involved parties ${ }^{(17)}$.

In view of the absence of standardized adverse event protocols and second victim support procedures and a perceived need for healthcare organizations to assist healthcare professionals involved in medical assistance errors, this study aimed to include in a protocol built with methodological accuracy actions which nursing staff understand as necessary.

The research question was: What interventions should be included in a protocol that provides guidance on organizational procedures for responding to serious adverse events involving nursing staff?

The objective of this study was to ascertain what measures and interventions should be included in an institutional response protocol in the face of serious adverse events which involve nursing staff.

\section{METHOD}

\section{STUdY TYPE}

Descriptive exploratory study.

\section{SCENARIO}

A descriptive exploratory study was conducted with 248 nurses in the Autonomous Community of Madrid, Spain.

\section{DATA COLLECTION}

Data was collected using paper and electronic versions of a non-validated questionnaire designed specifically for the purposes of this study following a literature review and applied between February and October 2016 $6^{(18)}$.

The questionnaire contained sociodemographic and occupational questions (sex, age, years of work experience, and type of healthcare facility and service) and a closedended multiple choices question regarding the interventions that should be included in the support protocol to the professionals involved in an adverse event. An open-ended final question with an "Others" option was also included.

\section{DATA ANALYSIS AND TREATMENT}

Data analysis was performed with the statistical software package SPSS Statistics 23.0 using basic descriptive data, the number and percentage of cases in each category, and minimum, maximum, mean, and standard deviation values. Variable groups were compared using the chi-squared test.

\section{ETHICAL ASPECTS}

This study was authorized by the Colegio Oficial de Enfermeria de Madrid (the Official Nursing College of Madrid) under the registration number 2016407176. The anonymity and confidentiality of study participants was maintained in accordance with Spain's Data Protection Act (Law 15/1999). Nurses who undertook the ten editions of the course "the Role of Nurses in Patient Safety" provided by the Colegio Oficial de Enfermeria de Madrid were requested to participate in the course on a voluntary basis.

\section{RESULTS}

The final sample comprised 248 nurses ( $\mathrm{N}=248), 90.3 \%$ $(n=224)$ of whom were women and $9.7 \%(n=24)$ men. The average age of the participants was 36.3 years $(\mathrm{SD}=10.5$, 
range 22 to 62 years). Almost three-quarters of the nurses $(72.6 \%, n=180)$ worked in hospitals and $25.8 \%(n=64)$ in other types of healthcare facilities (primary care/outpatient clinics). The average number of years of work experience was 14.6 ( $\mathrm{SD}=10.8$, range $0-42$ years).

Table 1 shows the interventions that nurses would like to see included in a second victim support protocol developed by their health organization. The results (number of participants, percentage, and chi-squared test) are shown by healthcare service type (hospitals or primary care centers/outpatient clinics). In this respect, the category hospital is broken down into the categories surgical unit, hospital unit, and specialist services, with the latter encompassing intensive care units (ICUs) and hospital and out-of-hospital emergencies.

Table 1 - Interventions that nurses would like to see included in a protocol by type of service - Nurses from the Autonomous Community of Madrid, Spain, 2016

\begin{tabular}{|c|c|c|c|c|c|c|c|}
\hline \multirow{2}{*}{ Interventions } & \multicolumn{4}{|c|}{ Service $n(\%)$} & \multirow{2}{*}{$\begin{array}{l}\text { Total } \\
(\%)\end{array}$} & \multicolumn{2}{|c|}{ Chi-squared test } \\
\hline & $\begin{array}{c}\text { Surgical } \\
\text { units }\end{array}$ & $\begin{array}{l}\text { Hospital } \\
\text { units }\end{array}$ & $\begin{array}{l}\text { Special } \\
\text { services }\end{array}$ & $\begin{array}{c}\text { Primary } \\
\text { care }\end{array}$ & & $\chi 2(1)$ & p-value \\
\hline Counseling & & & & & & 0.869 & 0.833 \\
\hline Yes & $31(81.6)$ & $89(80.9)$ & $29(87.9)$ & $52(82.5)$ & 82.4 & & \\
\hline No & $7(18.4)$ & $21(19.1)$ & $4(12.1)$ & $11(17.5)$ & & & \\
\hline \multicolumn{3}{|c|}{ Advice from the legal services department } & & & & 7.39 & 0.06 \\
\hline Yes & $30(78.9)$ & $93(84.5)$ & $33(100)$ & $55(87.3)$ & 86.5 & & \\
\hline No & $8(21.1)$ & $17(15.5)$ & & $8(12.7)$ & & & \\
\hline \multicolumn{3}{|c|}{ Advice on assurances and legal safe guards } & & & & 7.03 & 0.084 \\
\hline Yes & $17(44.7)$ & $73(66.4)$ & $24(72.7)$ & $44(69.8)$ & 64.8 & & \\
\hline No & $21(55.3)$ & $37(33.6)$ & $9(27.3)$ & $19(30.2)$ & & & \\
\hline \multicolumn{3}{|c|}{ Guidance on how to record events } & & & & 2.493 & 0.476 \\
\hline Yes & $23(60.5)$ & $75(68.2)$ & $25(75.8)$ & $46(73)$ & 69.3 & & \\
\hline No & $15(39.5)$ & $35(31.8)$ & $8(24.2)$ & $17(27)$ & & & \\
\hline \multicolumn{3}{|c|}{ Communication strategies workshop } & & & & 7.979 & $0.045^{*}$ \\
\hline Yes & $16 a(42.1)$ & $66 b(60)$ & $22 b(66.7)$ & $43 b(68.3)$ & 60.2 & & \\
\hline No & $22 \mathrm{a}(57.9)$ & $44 b(40)$ & $11 \mathrm{~b}(33.3)$ & $20 b(31.7)$ & & & \\
\hline Refresher workshop & & & & & & 3.643 & 0.303 \\
\hline Yes & $16(42.1)$ & $60(54.5)$ & $21(63.6)$ & $36(57.1)$ & 54.5 & & \\
\hline No & $22(57.9)$ & $50(45.5)$ & $12(36.4)$ & $27(42.9)$ & & & \\
\hline \multicolumn{2}{|c|}{ Secondment of second victim } & & & & & 5.821 & 0.121 \\
\hline Yes & $1(2.6)$ & $15(13.6)$ & $7(21.2)$ & $10(15.9)$ & 13.5 & & \\
\hline No & $37(97.4)$ & $95(86.4)$ & $26(78.8)$ & $53(84.1)$ & & & \\
\hline \multicolumn{3}{|c|}{ Permanent transfer of second victim } & & & & 11.809 & $0.008^{* *}$ \\
\hline Yes & & 1a $(0.9)$ & $4 b(12.1)$ & $3 a, b(4.8)$ & 3.3 & & \\
\hline No & $38 \mathrm{a}(100)$ & 109a (99.1) & $29 b(87.9)$ & $60 a, b(95.2)$ & & & \\
\hline \multicolumn{2}{|l|}{ Other } & & & & & 15.323 & $0.002^{* *}$ \\
\hline Yes & $5 a(13.2)$ & $12 \mathrm{a}(10.9)$ & $13 b(39.4)$ & $14 a, b(22.2)$ & 18 & & \\
\hline No & 33a $(86.8)$ & $98 a(89.1)$ & $20 \mathrm{~b}(60.6)$ & $49 a, b(77.8)$ & & & \\
\hline
\end{tabular}

a-b: Comparisons between columns: lowercase letters indicate statistically significant differences adopting a significance level of $\mathrm{p}<0.05$ (Bonferroni). ${ }^{*}$ $\mathrm{p}<0.05 ;{ }^{* *} \mathrm{p}<0.01$.

The results show that $86.5 \%$ of the nurses would like to receive specialist advice as to the legal consequences of involvement in a serious adverse event from the legal services department of their health organization, while $82.4 \%$ believe it is necessary to receive counseling from specialists to cope with psychological distress and posttraumatic stress disorder in the aftermath of a medical error resulting in serious harm to the patient.
Over two-thirds (69.3\%) of the participants showed that they would like to receive guidance on how to record facts about the events, such as the people involved in the event, on the patient's medical records, while $64.8 \%$ of the nurses showed that they would like to receive advice on assurances and legal safeguards in relation to the health organization's adverse event recording and notification system. 
With respect to communication strategies workshops, $60.2 \%$ of the interviewees showed that they would like to receive training on techniques for communicating bad news and how to inform the patient and his/her family. However, a statistically significant difference was observed between nurses who work in surgical units, where 22 participants (57.9\%) showed that they would not like to receive training $(\mathrm{p}<0.045)$, and professionals from hospital units, specialist services, and primary care centers/ outpatient clinics, who suggested that they would like to receive training.

Over half of the nurses (54.5\%) endorsed the inclusion of refresher workshops on procedures and nursing techniques.

Permanent transfer in cases of medical error resulting in serious harm to the patient was one of the less favored interventions, with only $3.3 \%$ of participants supporting this measure, while while only a small proportion of professionals (13.5\%) endorsed secondment in cases of medical error resulting in serious harm to the patient. Almost $90 \%$ of the respondents confirmed that they would not like to be transferred from the service or unit neither temporarily nor permanently in the case of involvement in an adverse event.

Responses to the item Other included paid and unpaid leave after an adverse event (18\%), the latter being the most common suggestion among professionals from primary care centers/outpatient clinics.

Table 2 summarizes the types of interventions that the nurses would like to see included in a second victim support protocol.

Table 2 - Summary of the interventions that nurses would like to see included in a second victim support protocol - Nurses from the Autonomous Community of Madrid, Spain, 2016.

\begin{tabular}{|c|c|}
\hline Ranking of response options & Total n (\%) \\
\hline Item 1: Legal advice & $211(86.5)$ \\
\hline Item 2: Counseling & $201(82.4)$ \\
\hline $\begin{array}{l}\text { Item 3: Guidance on how to record events on the } \\
\text { patient's medical record }\end{array}$ & $169(69.3)$ \\
\hline $\begin{array}{l}\text { Item 4: Advice on assurances and legal safeguards } \\
\text { in relation to the health organization's adverse } \\
\text { event recording and notification system }\end{array}$ & $158(64.8)$ \\
\hline Item 5: Communications strategies workshop & $147(60.2)$ \\
\hline $\begin{array}{l}\text { Item 6: Refresher workshop on procedures and } \\
\text { nursing techniques }\end{array}$ & $133(54.5)$ \\
\hline $\begin{array}{l}\text { Item 7: Other measures such as paid and unpaid } \\
\text { leave after a serious adverse event. }\end{array}$ & $61(18)$ \\
\hline \multicolumn{2}{|l|}{$\begin{array}{l}\text { Item 8: Transfer or secondment of the second } \\
\text { victim to another unit/service ... }\end{array}$} \\
\hline ...temporary & $33(13.5)$ \\
\hline ...permanent & $8(3.3)$ \\
\hline
\end{tabular}

\section{DISCUSSION}

The present study analyzes the type of interventions that should be included in an organizational protocol for responding to serious adverse events involving nursing staff.
The interventions prioritized by the nurses were advice from the legal services department and counseling, regardless of the type of healthcare service in which they worked. The results also highlight a perceived need for advice on legal safeguards in relation to notifying adverse events and guidance on how to record events on the patient's medical records.

The results show that the possibility of disciplinary and/ or legal action and post-traumatic stress are primary concerns of the respondents in relation to adverse events.

These findings are consistent with the results of other studies. A group of healthcare professionals and law experts who participated in a study that explored "the opportunities and ethical-legal barriers of medical error communication and apology" considered that training to improve knowledge about the legal aspects and communication of adverse events was necessary to overcome the barriers that limit the disclosure and communication of medical errors arising from the "fear of legal action, the media, or the reaction of the profession" ${ }^{\prime \prime 17)}$.

A study carried out in a hospital in Europe with professionals involved in medical errors showed that the majority of participants expressed the need for organizational support and information about the subsequent investigation process $^{(7)}$.

When care delivery results in unexpected patient outcomes, the majority of patients want to receive information promptly. Furthermore, patients greatly appreciate an apology from the involved health professional and assurance that appropriate measures are being taken to avoid similar occurrences in the future ${ }^{(19)}$.

Our findings also show that over half of the participating professionals, including both those from primary care and hospital and specialist services (urgent and emergency care and ICUs), would like to receive communications strategies workshop to be able to properly communicate medical errors to affected patients and their families.

Various authors have highlighted that frank and honest disclosure of an adverse event to the patient and his/her family can relieve the anxiety and emotional distress felt by the professionals involved ${ }^{(4)}$. Likewise, good communication can help restore the healthcare professional-patient relationship: "The main opportunity provided by communication is the strengthening of doctor-patient/family trust" ${ }^{\prime(17)}$. Scientific evidence shows that good communication in routine clinical practice strengthens the care team, improves patient safety, and leads to a reduction in medical errors ${ }^{(18)}$.

A number of international studies have shown that healthcare professionals lack adverse event disclosure and communication skills and are largely interested in receiving training to develop these skills ${ }^{(3,7)}$. A study conducted with Spanish healthcare professionals revealed that only $17.4 \%$ of doctors and $19.1 \%$ of nurses had received training in how to properly communicate an adverse event to the patient ${ }^{(20)}$.

Another study exploring notification and disclosure of adverse events emphasizes the importance of implementing strategies to ensure open and frank communication 
between professionals and with patients, such as debriefing at shift change and sessions for conducting the formative assessment of incidents ${ }^{(16)}$.

Besides strategies to foster effective medical error communication and apology, our study participants emphasized the importance of legal safeguards, with the assurance of appropriate procedures for all involved parties ${ }^{(17)}$. Studies show that a nonpunitive response to medical error is an important aspect of adverse event management ${ }^{(14)}$.

The large majority of the professionals interviewed endorsed the provision of refresher workshops directed at common techniques and procedures that result in medical error, such as the application of high risk medications for example. Optimizing the skills of nurses and the provision of refresher and specialist training in specific procedures can also help improve patient safety culture ${ }^{(18)}$.

Scientific evidence shows that medication errors, particularly those involving potentially dangerous parenteral drugs, are the most common safety incidents in urgent care services, ICUs, and surgical units, and that the majority of these incidents involve nursing staff ${ }^{(21)}$. A study conducted in a pediatric cardiothoracic intensive care unit in a hospital in the United States showed that medication errors resulting in patient harm were reduced by initiating quality improvement interventions that included nursing education. Education activities included theoretical and practical refresher courses on the safe use of high risk medications. The nursing professionals were subsequently audited and assessed to check compliance with the "five steps of safe medication administration", which proved to be very effective ${ }^{(14)}$.

In line with our study findings, other studies recognize the need to implement improvements in patient safety, including training, guidance, and research ${ }^{(17,19)}$.

Recent studies exploring the consequences of medical errors for involved professionals have raised crucial questions about the need to acknowledge the psychological impact of adverse events on second victims and the duty of organizational leaders to respect their rights ${ }^{(8)}$. Initiatives providing psychological support to victims of preventable adverse events, such as those promoted by the MITSS program, are being implemented in countries like the United States ${ }^{(9)}$.

It is important not to overlook the fact that adverse events resulting in serious harm to the patient can affect the social image of the involved healthcare organization. Initiatives such as the development of guidelines with recommendations on first and second victim support are beginning to take shape across a number of healthcare organizations. These initiatives include crisis plans and checklists of actions designed to provide adequate response and safeguard the organization's reputation ${ }^{(22-23)}$.

Our results show that the majority of respondents confirmed that they would not like to be transferred from the service or unit neither temporarily nor permanently in the case of involvement in an adverse event. This type of enforced measure may be counterproductive because it is perceived by healthcare professionals as punitive or disciplinary.

The findings of the present study are particularly relevant to the nursing profession. Given the key role played by nurses in patient safety, adverse event victim support protocols should incorporate the priorities and expectations of nursing professionals recognized for the first time by this study. It is important to note that these results may be extrapolated to other contexts given that the proposed interventions were endorsed by a large sample of nurses. In this respect, they constitute a valuable input for clinical managers and organizational leaders and may be applied to a range of healthcare settings in different countries with a view to promoting a culture of patient safety.

The main innovation brought by this study is a new tool from the patient safety point of view that allows healthcare organizations to adopt a multidisciplinary approach to providing legal, psychological, and occupational support to healthcare professionals involved in medical errors resulting in serious harm to the patient. Future research should examine the extent of implementation of support protocols across healthcare organizations and assess satisfaction levels and perceived quality among professionals.

One of the limitations of this study is that the participants belong to the same category of healthcare professionals, meaning that it is not possible to extrapolate the results to other types of professionals. Furthermore, selection bias occurred due to the nonrandom sampling design. A broader and more comprehensive study should be conducted to address these aspects.

\section{CONCLUSION}

The findings show that respondents prioritized counseling and legal advice to address the psychological, legal, and professional consequences of being involved in adverse events. However, the results also show that the nurses feel it is necessary to be informed about assurances of anonymity, confidentiality, and non-punishment in relation to the healthcare organization's medical error notification system.

Furthermore, the participants showed that they would like to receive guidance on how to properly record medical errors on the patient's medical records, training workshops in adverse event communication and disclosure, and refresher training. However, they did not endorse the compulsory transfer of healthcare professionals involved in adverse events to other units or services.

This study highlights the importance of understanding and implementing the perceived needs of nursing professionals in relation to second victim support protocols. 


\section{RESUMEN}

Objetivo: Conocer las medidas y acciones que debería incluir un protocolo de respuesta institucional frente a eventos adversos graves que involucren al equipo de enfermería. Método: Estudio exploratorio descriptivo a través de cuestionario con una muestra de profesionales de Enfermería, colegiados en Madrid, España. Resultados: Participaron 248 profesionales de Enfermería. Un protocolo de respuesta institucional frente a eventos adversos graves que involucren al equipo de enfermería debería incluir el asesoramiento jurídico (86,5\%) y psicológico $(82,4 \%)$ como intervenciones prioritarias. Un 69,3\% de los enfermeros son partidarios del asesoramiento sobre cómo registrar el evento adverso en la historia clínica. Un 64,8\% desearían recibir asesoramiento sobre las garantías y seguridad jurídica del sistema de notificación de errores. Un 54,5\% de los enfermeros apoyan protocolizar talleres de reciclaje de técnicas. El cambio o permuta forzosa de servicio de manera permanente, es una de las estrategias menos deseadas entre los profesionales (3,3\%). Conclusión: Los enfermeros reclaman recibir asesoramiento psicológico y jurídico, técnicas de comunicación y reciclaje y no ser cambiados de servicio, para abordar las consecuencias posteriores de un evento adverso.

\section{DESCRIPTORES}

Seguridad del Paciente; Errores Médicos; Errores de Medicación; Grupo de Enfermería.

\section{RESUMO}

Objetivo: Conhecer as medidas e ações que deveriam incluir um protocolo de resposta institucional diante de eventos adversos graves que envolvam a equipe de enfermagem. Método: Estudo exploratório descritivo por meio de questionário com uma amostra de profissionais de Enfermagem, colegiados em Madri, Espanha. Resultados: Participaram 248 profissionais de Enfermagem. Um protocolo de resposta institucional diante de eventos adversos graves que envolvam a equipe de enfermagem deveria incluir a assessoria jurídica $(86,5 \%)$ e psicológica $(82,4 \%)$ como intervenções prioritárias. Cerca de 69,3\% dos enfermeiros são partidários da assessoria sobre como registrar o evento adverso na história clínica. Aproximadamente $64,8 \%$ desejariam receber assessoria sobre as garantias e segurança jurídica do sistema de notificação de erros. Cerca de 54,5\% dos enfermeiros apoiam protocolar oficinas de reciclagem de técnicas. A mudança ou troca forçosa de serviço de modo permanente é uma das estratégias menos desejadas entre os profissionais $(3,3 \%)$. Conclusão: Os enfermeiros reivindicam receber assessoria psicológica e jurídica, técnicas de comunicação e reciclagem e não ser trocados de serviço, para abordar as consequências posteriores de um evento adverso.

\section{DESCRITORES}

Segurança do Paciente; Erros Médicos; Erros de Medicação; Equipe de Enfermagem.

\section{REFERENCES}

1. Torijano-Casalengua ML, Astier-Peña P, Mira-Solves JJ, Sociedad Española de Medicina Familiar y Comunitaria.. El impacto que tienen los eventos adversos sobre los profesionales sanitarios de atención primaria y sus instituciones. Aten Primaria. 2016;48(3):143-6.

2. Edrees H, Connors C, Paine L. Implementing the RISE second victim support programme at the Johns Hopkins Hospital: a case study. BMJ Open [Internet]. 2016 [cited 2018Jul 9];6:e011708. Available from: https://www.ncbi.nlm.nih.gov/pubmed/27694486/

3. Wu AW, Steckelberg RC. Medical error, incident investigation and the second victim: doing better but feeling worse? BMJ Qual Saf [Internet]. 2012 [cited 2018 Feb 15];21(4):267-70. Available from: http://www.ncbi.nlm.nih.gov/pubmed/22213379

4. Lewis EJ, Baernholdt MB, Yan G, Guterbock TG. Relationship of adverse events and support to RN burnout. J Nurs Care Qual. 2015;30(2):144-52.

5. Seys D, Wu AW, Van Gerven E, Vleugels A, Euwema M, Panella M, et al, Health care professionals as second victims after adverse events: a systematic review. Eval Health Prof. 2013;36(2):135-62.

6. Mira JJ, Carrillo I, Lorenzo S, Ferrús L, Silvestre C, Pérez-Pérez P, et al. The aftermath of adverse events in Spanish primary care and hospital health professionals. BMC Health Serv Res. 2015;15:151.

7. Ullström S, Sachs MA, Hansson J, Øvretveit J, Brommels M. Suffering in silence: a qualitative study of second victims of adverse events. BMJ Qual Saf [Internet]. 2014 [cited 2018 Feb 15];23(4):325-31. Available from: https://www.ncbi.nlm.nih.gov/pubmed/24239992

8. Sociedad Española de Calidad Asistencial. Recomendaciones para la respuesta institucional ante un evento adverso. Rev Calid Asis. 2016;31(1):42-54.

9. Grissinger M. Too many abandon the "second victims" of medical errors. PT [Internet]. 2014 [cited 2018 Feb 15];39(9):591-2. Available from: https://www.ncbi.nlm.nih.gov/pmc/articles/PMC4159062/

10. Seys D, Scott S, Wu A, Van Gerven E, Vleugels A, Euwema M, et al. Supporting involved health care professionals (second victims) following an adverse health event: aliterature review. Int J Nurs Stud. 2013;50(5):678-87.

11. Mira JJ, Lorenzo S, Navarro I. Hospital reputation and perceptions of patient safety. Med Princip Pract. 2013;23(1):92-94.

12. Taylor A. In response to the article, "Relationship of adverse events and Support to RN Burnout". J Nurs Care Qual. 2015;30(4):289.

13. Ferner RE. Medication errors. Br J Clin Pharmacol. 2012;73(6):912-6.

14. Keiffer S, Marcum G, Harrison S, Teske DW, Simsic JM. Reduction ofmedication errors in a pediatric cardiothoracic intensive care unit. J Nurs Care Qual. 2015;30(3):212-9.

15. The Joint Commission. The essential role of leadership in developing a safety culture. Sentinel Event Alert. Oakbrook Terrace; 2017.

16. Astier-Peña MP, Torijano-Casalengua ML, Olivera-Cañadas G. Setting priorities for patient safety in Primary Care. Aten Primaria. 2015;48(1):3-7.

17. Giraldo P, Corbella J, Rodrigo C, Comas M, Sala M, Castells X. Análisis de las barreras y oportunidades legales-éticas de la comunicación y disculpa de errores asistenciales en España. Gac Sanit. 2016;30(2):117-20.

18. Ricciardi R. AHRQ focuses on ambulatory patient safety. J Nurs Care Qual. 2015;30(3):193-6. 
19. The Canadian Medical Protective Association. Disclosing harm from healthcare delivery [Internet]. Ottawa; 2015 [cited 2018 Feb 15]. Available from: https://www.cmpa-acpm.ca/static-assets/pdf/advice-and-publications/handbooks/com_15_disclosure_handbook-e.pdf

20. Mira JJ, Lorenzo S, Carrillo I, Ferrús L, Pérez-Pérez P, Iglesias F, et al. Something is wrong in the way we inform patients of an adverse event. Gac Sanit. 2015;29(5):370-4.

21. Valle MMF, Cruz EDA, Santos T. Medication incidents in an outpatient emergency service: documental analysis. Rev Esc Enferm USP. 2017;51:e03271. DOI: http://dx.doi.org/10.1590/S1980-220X2016033303271

22. Mira JJ, Lorenzo S, Carrillo I, Ferrús L, Pérez-Pérez P, Iglesias F, et al. Interventions in health organisations to reduce the impact of adverse events in second and third victims. BMC Health Serv Res. 2015;15:341.

23. Mira-Solves JJ, Carrillo I, Lorenzo S. What are hospitals and primary care doing to mitigate the social impact of serious adverse events. Gac Sanit. 2017;31(2):150-3. 